должна состоять из отдельных панелей, которые подлежат замене при определённой величине деструкции поверхностных слоёв ТЗП.

Представленные расчёты указывают на целесообразность проведения дальнейших работ по применению абляционных материалов для защиты кабин лесопожарных машин от интенсивного теплового воздействия

$$
* * *
$$

1. Данные Росстата по лесным пожарам [Электронный ресурс] - режим доступа: http://www.gks.ru/free_doc/new_site/business/sxles2.htm

2. Воробьёв, Ю.Л. Лесные пожары на территории России: Состояние и проблемы. МЧС России / Ю.Л. Воробьёв, В.А. Акимов, Ю.И. Соколов; Под общ. ред. Ю.Л. Воробьёва. - М.: ДЭКС-ПРЕСС, 2004. $312 \mathrm{c}$.

3. Цай, Ю.Т. Обзор исследований опасных и вредных факторов лесного пожара / Ю.Т. Цай, С.В. Стельмахович, И.В. Косов // Лесной вестник №1(32), 2004 г. - с. 14-24.

4. Цай, Ю.Т. Применение метода экспертных оценок для выбора структуры показателей при комплексной оценке безопасности лесных пожарных / Ю.Т. Цай // Лесной вестник №5(36), 2004 г. c. 94-104.

5. Сныткин, Г.В. Особенности лесных пожаров в разных формациях, типах леса и методы их тушения в лесах крайнего северо-востока Сибири / Г.В. Сныткин // Лесной вестник №5(20), 2001 г. - с. 37-44.

6. Cimander, S. Morita: Führender Feuerwehrfahrzeughersteller aus Japan [электронный ресурс]. - режим доступа http://www.fwnetz.de/2010/06/08/-morita-fuhrender-feuerwehrfahrzeughersteller-aus-japan/

7. Morita new concept car [электронный pecypc] - Morita group. - режим доступа http://www.morita119.com/en/innovation/awards/in-dex.html

8. Машины для тушения лесных пожаров Ивеко МАГИРУС [электронный ресурс] - режим доступа http://www.magirus.ru/forest.shtml

9. Mert, A. AUTONOMOUS FIRE GUARD for Husqarna [электронный ресурс] - режим доступа http://aydinmert.net/

10. Лесопожарный агрегат ЛПА-521 [электронный ресурс] - УралВагонЗавод, Рубцовский филиал. режим доступа http://www.uvzrmz. ru/product/105/

11. Способ изготовления препрега с автоматическим контролем технологического процесса. Патент РФ № 2565709 от 21.09.2015 г.

12. Котенко, В.Д Вакуумная технология получения препрегов с высоким содержанием полимера/ В.Д Котенко, И.В. Глебов // Лесной вестник. - 2016. - Т. 20. - № 3. - С. 29-34.

13. Котенко В.Д. Вакуумная технология изготовления многослойных препрегов./ В.В. Абразумов, В.Д. Котенко, И.В. Глебов, Н.В Синюков// Научные тенденции: Вопросы точных и технических наук. Сборник научных трудов по материалам XII международной научной конференции 12 декабря 2017 г., - С.-Петербург. - с. 48-53.

14. Ермоченков М.Г. Математическое моделирование процессов, протекающих в древесине при термическом модифицировании/ Ермоченков М.Г., Семенов Ю.П.// Лесной вестник. Научноинформационный журнал.- М.: ГОУ ВПО МГУЛ. - 2012 - №4(87). - С 92-97

15. Ермоченков, М.Г. Прогнозирование свойств термически модифицированной древесины. - М.: Горячая линия - телеком 2017. $-220 \mathrm{c}$.

\title{
Аравенков А.А., Пасынков Ю.А. \\ Применение анализатора гармоник на основе широтно-импульсной модуляции в задаче оценки качества электрической энергии в системах электроснабжения общего пользования
}

Новосибирский Государственный Технический Университет (Россия, Новосибирск)

doi:10.18411/spc-12-02-2018-08

idsp: 000001:spc-12-02-2018-08

\section{Аннотация}

Статья посвящена рассмотрению метода измерения амплитуд и фаз гармонических составляющих сигналов основанного на широтно-импульсной модуляции и применению его в области оценки качества электрической энергии в системах электроснабжения общего пользования для измерения амплитуд сетевого напряжения и последующего расчета его коэффициента не синусоидальности. 
Задача оценки качества электрической энергии в системах электроснабжения является достаточно актуальной задачей, поскольку оно напрямую влияет на срок службы эксплуатируемого оборудования, а также на качество выпускаемой продукции. Одним из важных параметров характеризующий качество электрической энергии является коэффициент несинусоидальности. В соответствие с ГОСТ Р 30804.4.7-2013 для расчета коэффициента несинусоидальности необходимо произвести измерения гармоник с номерами Hmin=1 по Hmax=40 для основной частоты $\mathrm{f} 0=50$ Гц с погрешностью не хуже $5 \%$ [1].

Сегодня, основным методом, используемым для измерения амплитуд гармонических составляющих электрических сигналов, является дискретное преобразование Фурье [2], а также производные от него алгоритмы, например, быстрое преобразование Фурье (БПФ) с прореживанием по времени. Все эти методы являются цифровыми, поэтому на первом этапе необходимо произвести оцифровку сигнала с помощью аналого-цифрового преобразователя, а затем используя процессор и специальные алгоритмы произвести расчет интересующих гармоник. Отметим, что этим алгоритмам присуще такое свойство как элайзинг, которое приводит к тому, что высокочастотные составляющие сигнала накладываются на низкочастотные. Для предотвращения этого эффекта частота дискретизации должна быть достаточно высокой и сигнал должен быть надлежащим образом отфильтрован перед оцифровкой. Другой проблемой ДПФ является высокие требования к вычислительным ресурсам и объёмам памяти необходимым при вычислении гармоник, что вызывает трудности его применения в микроконтроллерах общего назначения. Тоже самое относится и к алгоритмам БПФ. С одной стороны, они сокращают количество операций требуемых для вычисления гармоник, с другой являются достаточно сложными, что приводит к дополнительным затратам вычислительных ресурсов при их реализации.

Метод измерения амплитуд и фаз гармоник на основе широтно-импульсной модуляции (ШИМ) [3 - 5] в отличие описанных выше может быть реализован в аналоговом виде, что позволит значительно сократить требуемые вычислительные ресурсы. Наиболее важным элементом данного метода является формируемые широтно-импульсные сигналы (ШИС), от которых в наибольшей степени зависит точность измерения амплитуд и фаз гармоник. Главными параметрами, характеризующими ШИС являются: количество импульсов ШИС за один период исследуемой гармоники $\mathrm{N}$, количество точек в одном импульсе ШИС Р (дискретность ШИС) [3]. Для того, чтобы обеспечить точность измерения гармоник с погрешностью 5 \% необходимо формировать ШИС с минимум 8 импульсами ШИС за один период исследуемой гармоники $\mathrm{N}$ и минимум 10 точками в одном импульсе ШИС Р. Другой важной деталью, которую необходимо учесть при проектировании подобных анализаторов гармоник является влияние старших гармоник на погрешность определения младших [5]. Для того, чтобы избежать этого влияние необходимо отфильтровать входной сигнал и выбрать количество импульсов ШИС равное Нmax+4, где Hmax - номер наивысшей гармоники, которую необходимо измерить. Следовательно, количество импульсов ШИС за один период исследуемой гармоники $\mathrm{N}$ $=40+4=44$. Отсюда, частота, требуемая для формирования ШИС $\mathrm{fclk}=\mathrm{f0} * \mathrm{Hmax}^{*} \mathrm{~N} * \mathrm{P}=50 * 40 * 44 * 10=880000=880 \quad$ кГц. Bce современные микроконтроллеры могут обеспечить подобную частоту дискретизации. На рис. 1 представлена функциональная схема разработанного анализатора гармоник. Здесь: 1 фильтр нижних частот, 2 - инвертирующее устройство, 3 и 5 - аналоговые ключи, 4 и 6 - налоговые интеграторы, 7 - микроконтроллер со встроенными АЦП. 


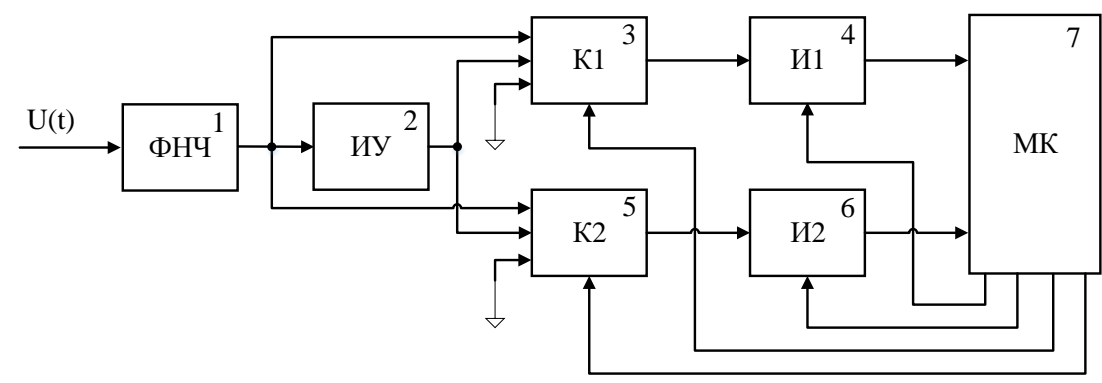

Рис.1. Функииональная схема анализатора гармоник.

$$
* * *
$$

1. ГОСТ Р 30804.4.7-2013.Общее руководство по средствам измерений и измерениям гармоник и интергармоник для систем энергоснабжения и подключаемым к ним техническим средств. - Введ. 2013-03-25. - М.: Изд-во стандартов, 20,31. - 39 с.

2. Айфичер, Эммануил С., Джервис, Барри У. Цифровая обработка сигналов: практический подход, 2-е издание. : Пер. с англ. - М.: Издательский дом «Вильямс», 2008 - 992 с. : ил. - Парал. тит. англ.

3. Аравенков А.А. Анализатор гармоник на основе широтно-импульсной модуляции / А.А. Аравенков, Ю.А. Пасынков // Ползуновский вестник. - 2015. - № 3. - С. 120-125.

4. Аравенков А.А. Анализатор гармоник на основе широтно-импульсной модуляции / А.А. Аравенков, Ю.А. Пасынков // Наука. Технологии. Инновации / Материалы всероссийской научной конференции молодых ученых в 4-х частях. - 2012. - № 2. - С. 10-11.

5. Аравенков А.А. Исследование влияния спектра широтно-импульсного сигнала на погрешность определения амплитуды гармоник в анализаторе гармоник на основе широтно-импульсной модуляции / А.А. Аравенков, Ю.А. Пасынков // Научный вестник. - 2017. - №. - С. 42-54.

6. Пат. 2564831C1 Российская Федерация, МПК7 G 01 R 23/16. Анализатор гармоник [Текст] / Аравенков А.А., Пасынков Ю.А.; заявитель и патентообладатель Федеральное государственное бюджетное образовательное учреждение высшего профессионального образования "Новосибирский государственный технический университет"- № 2014117408/28; заявл. 29.04.2014; опубл. 10.10.2015, Бюл. № 28. - 6 с. : ил.

7. Пат. 131496U1 Российская Федерация, МПК7 G 01 R 23/16. Анализатор гармоник [Текст] / Аравенков А.А., Пасынков Ю.А.; заявитель и патентообладатель Федеральное государственное бюджетное образовательное учреждение высшего профессионального образования "Новосибирский государственный технический университет"- №. 2012118134/28; заявл. 03.05.2012; опубл. 20.08.2013, Бюл. № 23. - 7 с. : ил.

8. Аравенков А.А. Метод анализа параметров гармонических составляющих сигнала основанного на широтно-импульсной модуляции с цифровым интегрированием и переключением сигналов / А.А. Аравенков, Ю.А. Пасынков // Перспективы науки, образования и бизнеса в цифровой экономике: сборник статей Международной научно-практической конференции (26.12.2017 г., г. Москва). [Электронный ресурс]- М.: Импульс, 2017. - С. 617-621.

9. Аравенков А.А. Разработка анализатора гармоник на основе широтно-импульсной модуляции с аналоговыми ключами и интеграторами / А.А. Аравенков, Ю.А. Пасынков // Научный диалог: Вопросы точных и технических наук. Сборник научных трудов, по материалам ХІІІ международной научно-практической конференции 16 января 2018 г. Изд. ЦНК МНИФ «Общественная наука», 2018. - C. $42-44$.

\section{Афанасьева Д.В., Маркова Е.А., Русинова Н.Г., Щенникова Т.В. Оптимизация работы вентиляционной установки на базе кинотеатра синема 5}

Чувашский государственный университет им. И.Н.Ульянова (Россия, Чебоксары)

doi:10.18411/spc-12-02-2018-09

idsp: 000001:spc-12-02-2018-09

\section{Аннотация}

В работе представлен вариант оптимизации работы вентиляционной установки для создания комфортных условий в кинозале, дается характеристика существующего положения, выполнены экономические расчеты при внедрении автоматизации оборудования. 